\title{
Resourcing a sustainable future
}

\section{We must resource present and future generations sustainably. But how? Jen Roberts and Anthea Lacchia report on an international summer school that is building a global community to bridge disciplines and sectors, and tackle sustainable resource extraction}

\footnotetext{
mmense and rapid societal and technical changes are necessary to achieve a low-carbon future.
} Globally, most nations have committed to meeting the goals outlined in the United Nations Paris Agreement, but the changes in technologies anticipated to achieve these goals, and the minerals and metals that are used in their manufacture, place new and unprecedented pressure on Earth's resources. This is on top of changing needs due to global population growth, rising standards of living, and potentially large shifts in the distribution of populations owing to the climate crisis.

Determining how we will resource present and future generations in a sustainable way is a complex and global endeavour of rising importance. The inaugural Researching Social Theories, Resources, and Environment (ReSToRE) International Summer School (https://www.icrag-centre. org/restore/) brought together a group of 42 geologists and social scientists, all at an early-career stage, from 28 nationalities (of which 19 are developing countries) to tackle the question of how society should meet the challenge of providing water, energy and mineral resources in a sustainable way. Participants concluded that inclusive, collaborative problem-solving that embraces different perspectives is essential in addressing such complex and thorny topics; the circular economy, which is inherently multidisciplinary and collaborative, is key to sustainable resourcing; and the way forward requires the combined efforts of those working across the natural and social sciences, in academia, industry and in government.

\section{Course vision}

Hosted by the Irish Centre for Research in Applied Geosciences (iCRAG), the summer school took place at University College Dublin, Ireland, in July 2019. Director of iCRAG, Murray Hitzman, said: "Moving forward for sustainable development is very complicated. There are challenges in terms of Earth resources and energy, and also in terms of how people perceive these challenges and sustainable development more generally. These are critical issues and this summer school is trying to help to tackle these, not just in one society, but in multiple societies".

Attendance at the summer school was competitive, and financial support was available for half of the participants due to sponsorship from the International Union of Geological Sciences (IUGS), the United Nations Educational, Scientific and Cultural Organization (UNESCO), and industry sponsors. A quarter of the participants were from the extractive industries (such as mining, petroleum, and related services) and the remainder from academia. They brought together expertise in geology, economics, ecology, business, law, engineering, and communications. Women constituted over a third of participants, and all attendees were within ten years of completing their studies.

The programme aimed to harness the diverse experience and skills of the participants, and created a space for interdisciplinary and visionary collaboration and knowledge sharing. Working in teams, attendees were challenged to define the problem, prioritise needs and derive solutions across four themes that spanned both local and global issues relating to the resourcing and consumption of Earth's materials: 1) Community engagement in Earth resource extraction and use;

2) Societal perceptions of the extraction industry; 3) Earth resources and the circular economy; and 4) Ethical and responsible sourcing of Earth resources.

The four topics were identified by a team of world-leading scholars, practitioners, and stakeholders, many of whom acted as expert mentors during the week. The topics are considered to be critical to the global challenge of sustainable resourcing of future generations. Crucially, there are no simple solutions to these problems, and all require an interdisciplinary and multiperspective approach.

In line with the summer school ethos, the team of mentors and other contributors was also diverse. Representing ten different nationalities (including three from developing countries), the team's expertise covered multiple disciplines and career stages from across industry, government and academia, including Cardiff University (UK), Plymouth University (UK), Newcastle University London (UK), Nottingham University Business School (UK), University of Strathclyde (UK), University of Groningen (Netherlands), Shinglespit Consultants Inc. (Canada), Cornell University (US) and PetraScience Consultants (Canada), as well as IUGS, UNESCO, iCRAG, Geoscience Ireland and Geological Survey Ireland.

Dr Ozlem Adiyaman Lopes from UNESCO's Division of Ecological and Earth Sciences said "this course is asking the right questions at the right time and the mix of social scientists and geoscientists and environmental scientists together is a triangle we really need." Professor Wouter Poortinga, an environmental psychologist at Cardiff University, agreed that the summer school "puts a spotlight on the social relevance of these big societal

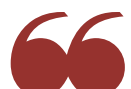
AN INCLUSIVE APPROACH REQUIRES AN INTERPLAY BETWEEN THE TECHNICAL AND NON-TECHNICAL WORLDS, BRIDGING POLICY, INDUSTRY, PRACTITIONERS AND ACADEMIA, AND UNITING GEOSCIENCE AND ENGINEERING WITH SOCIAL AND POLITICAL SCIENCE

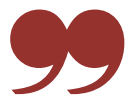


challenges". And these challenges involve everyone, as Dr Judy Muthuri, an expert in corporate social responsibility at Nottingham University, explained: "Sustainable resource development requires a collective effort from everybody. When you talk about governance of resource, there is a role for every actor in society to play if the UN's Sustainable Development Goals are to be realised".

\section{Cross-cutting themes}

The outcomes of the week's discussions highlighted the necessity for a long-term adaptive and continuous programme of activity. A key message is that the different actors necessary for resourcing a sustainable future cannot be considered in isolation. Consumer demand, business practices, environmental and societal impacts, community involvement in decision-making and development are all intrinsically interlinked in a non-linear chain that interweaves resource supply, use and reuse. Failure to consider resourcing issues though a collective lens will not support effective and efficient change.

An inclusive approach requires an interplay between the technical and nontechnical worlds, bridging policy, industry, practitioners and academia, and uniting geoscience and engineering with social and political science. This isn't easy. For many, working at the edge of one's discipline, and stepping into the space of others, can be challenging, and uncomfortable. Building collaboration across divides requires resources and support. Thus, interdisciplinary and cross-sectoral fora are fundamental if future resource development is to align with global sustainability goals.

wwAnother key theme was the clear opportunity for the resources chain to embrace the circular economy. A responsible resources sector will be clean and efficient, with reduced, managed and, where possible, reused waste. Some companies are already moving towards such a circular resource economy, but there is huge scope to do more. Enabling a circular economy requires transparent and collaborative input from all stakeholders, clear connections between producers, markets and consumers, and facilitation by economic and societal factors, including consumer demand and supportive policies. The summer school participants

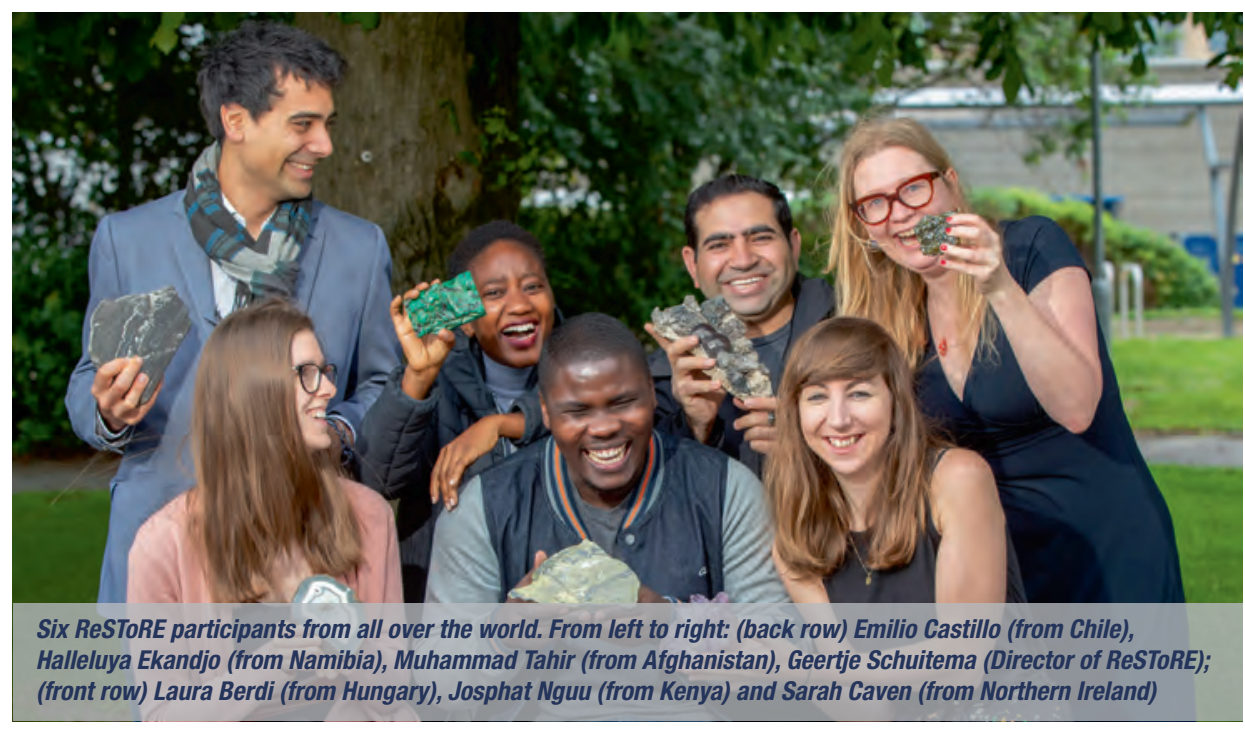

proposed that, in the circular economy, mining companies may even re-emerge as 'materials' or 'resources' companies. And once again, interdisciplinarity is fundamental, as Wouter Poortinga expressed, "the circular economy is inherently interdisciplinary-it forces us to think beyond disciplinary boundaries."

\section{The way forward}

So how do we move forwards, and fast? Immersive events like the ReSToRE summer school play a key role in creating a safe space for interdisciplinary connections. As Professor John Thompson from Cornell University and PetraScience Consultants remarked, "Interdisciplinary collaboration is absolutely key; the really innovative ideas happen when you're working with others at the edges of your expertise. That's where you will find innovation, within the common ideas that evolve from there." He added that "workshops like those at this summer school are one of the things that will actually move us forward, by defining the gaps, the research opportunities, the themes to pursue, policies that we might need to consider or advocate for-all of those things are going to lead to action, potentially new programmes, different ways of collaborating."

ReSToRE grew out of the Resources for Future Generations conference, which was chaired by John Thompson and held in Vancouver in summer 2018 (http:// www.rfg2018.org/). It is intended that the ReSToRE programme is just the beginning of a network of activities in a crucial field. As Dr Maeve Boland, of University College
Dublin's School of Earth Sciences and Geological Survey Ireland, explained: "One of the goals of the summer school is to facilitate the development of a global network of people working in this truly interdisciplinary area. We want to build a community that will share experiences to generate new knowledge, strengthen individual actors, and ultimately to advance us as a community working in a field of great societal relevance."

\section{Further Information}

A suite of summer school resources, including live-streamed videos of the presentations and discussions by expert mentors, blogs from the summer school participants, and movies capturing the ReSToRE programme can be found on the ReSToRE webpage: https://www.icragcentre.org/restore/.

iCRAG, the International Union of Geological Sciences and Geological Survey Ireland were the organising sponsors of ReSToRE, which was held under the patronage of UNESCO. Sponsorship came from BHP, Boliden, Rio Tinto, Teck, with additional support from the Irish Research Council and UCD College of Business.

The UN Paris Agreement (to date, 185 Parties have ratified of 197 Parties to the Convention); https://unfccc.int/ process/the-paris-agreement/status-ofratification

Dr Jen Roberts is Chancellor's Fellow at the University of Strathclyde, Glasgow.

Dr Anthea Lacchia is a Research Fellow in iCRAG at University College Dublin. 